$\mathrm{Y} \Delta \mathrm{K} 352 / 353$

ББК 66.3(0),124

DOI 10.22394/1682-2358-2018-1-25-32

T.I. Chernyaeva, Doctor of Sciences (Sociology), Professor of the Social Communication Department, Povolzbsky Institute of Management named after P.A. Stolypin, Branch of the Russian Presidential Academy of National Economy and Public Administration

Yu.A. Korsakov, Candidate of Sciences (Pbilosophy), Docent of the Graduate School of Public Administration of the Russian Presidential Academy of National Economy and Public Administration

\section{PROJECT PRACTICES \\ IN THE SYSTEM \\ OF TERRITORIAL \\ PUBLIC MANAGEMENT \\ IN THE SARATOV REGION}

The authors discuss the possibilities and limits of territorial public management, in the context of spatial development of Russia. Special focus is on the outcomes of the project session on Territorial Public Management School implemented in Povolzhsky Institute of Management named after P.A. Stolypin.

Key words and word-combinations: spatial development, territorial public management, project practices.
Т.И. ЧерняеВа, доктор сочиологческих наук, профессор кафедры социальньх коммуникаиии Поволжского института управления имени П.А. Стольпина - филиала Российской академии народного хозяйства и государственной службюг при Президенте РФ (email: tatcher@yandex.ru)

Ю.А. КорсакоВ, кандидат философских наук, доцент Вигсшей школьг государственного управления Российской академии народного хозяйства и государственной службь при Президенте PФ (email:yukors@yandex.ru)

\section{ПРОЕКТНЫЕ ПРАКТИКИ \\ В СИСТЕМЕ \\ ТЕРРИТОРИААЬНОГО \\ ОБЩЕСТВЕННОГО

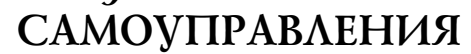 \\ САРАТОВСКОЙ ОБААСТИ}

Аннотация. Авторы анализируют возможности и ограничения территориального общественного самоуправления в контексте пространственного развития России. Особый акцент сделан на итогах проектной сессии Школы ТОС, реализованной в Поволжском институте управления имени П.А. Столыпина РАНХиГС.

Ключевые слова и словосочетания: пространственное развитие, территориальное общественное самоуправление, проектные практики.

$\mathrm{P}$ азрабатываемая с 2015 г. Стратегия пространственного развития России призвана укрепить экономическую эффективность, устойчивое развитие и безопасность регионов. Ее основные положения вкцючают приоритеты совершенствования системы расселения на территории Российской 
Федерации и механизмы стимулирования расселения в соответствии с приоритетными направлениями совершенствования системы расселения; направления изменения структуры экономики Российской Федераџии в региональном аспекте; перспективные конкурентные преимущества и экономическую специализаџию субъектов РФ в межрегиональном раздемении труда в соответствии с их типологической принадмежностью, учитывающие принџипы обеспечения согласованности приоритетов отраслевого и регионального развития. Кроме того, делается прогноз (оценка) потребности субъектов РФ в трудовых ресурсах с учетом перспективной экономической специализаџии и прогнозов социально-экономического развития соответствующих территорий; прогноз (оџенку) потребности в размещении и развитии федеральной инженерной, транспортной и соџиальной инфраструктуры с учетом перспективной экономической спеџиализаџии соответствующих территорий; предлагается перечень потенџиальных территорий опережающего соџиально-экономического развития, основанный на комплексной оџенке и анализе условий и потенџиалов пространственного развития Российской Федераџии; Ааются варианты территориального размешения национальных технологических платформ; направления интеграџии Российской Федераџии в единое евразийское и мировое экономическое пространство; состав макрорегионов на территории Российской ФеАераџии; результаты отнесения городов и регионов Российской Федераџии к опредеменным типам [1].

Сценарий сбалансированного развития выстраивается на поддержке агломерационных эффектов (девять центров по России), без которых невозможен подъем ВВП. Вместе с тем на другом краю этого тренда оказываются муниџипальные образования. Предполагается, что многие муниџипалитеты обладают собственными резервами Аля развития, в частности, природно-климатическими, пространственно-географическими, культурно-историческими. Специализация и внятный брендинг помогут обеспечить экономический рост Ааже отдаленным территориям [2] .

Очевидно, что успешность реализаџии Стратегии существенно зависит от сбалансированности интересов государственной вмасти и местного самоуправмения, вовлеченности населения, от активности субъектов территориального общественного самоуправления (ТОС).

В Саратовской области, в отличие от соседних Самарской, УАьяновской, Пензенской областей, наблюдается тенденџия к сокращению числа муниципальных образований (таблица) [3; 4].

Объединение и централизаџия муниџипальных образований в короткий срок нарушает сложившиеся практики управления территорией, привносит новые смыслы и порядки взаимодействия. Ситуация усугубляется тем, что законодательно не определены формы взаимоотношений органов местного самоуправления и органов территориального общественного самоуправления. Искмючение составляет возможность ТОС вносить в органы местного самоуправления проекты муниципальных правовых актов. Но формально не опреде- 
менные разграничения полномочий приводят к тому, что на местах устанавциваются свои порядки такого взаимодействия: иногда в уставах муниџипальных образований записано, что органы местного самоуправцения и органы ТОС определяют сферу совместной компетенции. ОАнако совместной компетенции у этих органов быть не может в силу их размичного характера - органы территориацьного общественного самоуправцения не обладают вцастными полномочиями в отличие от органов местного самоуправления. Их решения имеют общественный характер, соответственно, под вопросом оказывается сфера совместной компетенции [5] .

Число мунищипальных образований

по Пензенской, Самарской, Саратовской, Умьяновской обмастям на 1 января 2015 и 2017 гг.

\begin{tabular}{|c|c|c|c|c|c|c|c|c|c|}
\hline \multirow{5}{*}{ Область } & \multicolumn{9}{|c|}{ Муниципальные образования } \\
\hline & \multirow{4}{*}{ : } & \multicolumn{8}{|c|}{ в том числе по типам } \\
\hline & & \multirow{3}{*}{ 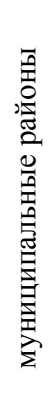 } & \multicolumn{2}{|c|}{$\begin{array}{c}\text { городские } \\
\text { округа }\end{array}$} & \multirow{3}{*}{ 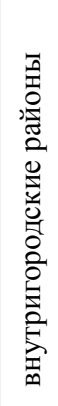 } & \multirow{3}{*}{ 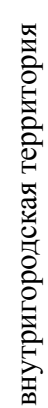 } & \multicolumn{3}{|c|}{ поселения } \\
\hline & & & \multirow{2}{*}{ 总 } & \multirow{2}{*}{ 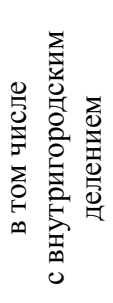 } & & & \multirow[b]{2}{*}{ 总 } & \multicolumn{2}{|c|}{$\begin{array}{l}\text { в том } \\
\text { числе }\end{array}$} \\
\hline & & & & & & & & 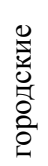 & 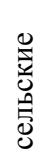 \\
\hline
\end{tabular}

2015

\begin{tabular}{|l|c|c|c|c|c|c|c|c|c|}
\hline Пензенская & 325 & 27 & 3 & - & - & - & 295 & 24 & 271 \\
\hline Самарская & 341 & 27 & 10 & - & - & - & 304 & 12 & 292 \\
\hline Саратовская & 396 & 38 & 4 & - & - & - & 354 & 39 & 315 \\
\hline Ульяновская & 167 & 21 & 3 & - & - & - & 143 & 31 & 112 \\
\hline
\end{tabular}

2017

\begin{tabular}{|l|c|c|c|c|c|c|c|c|c|}
\hline Пензенская & 325 & 27 & 3 & - & - & - & 295 & 24 & 271 \\
\hline Самарская & 342 & 27 & 10 & 1 & 9 & - & 296 & 12 & 284 \\
\hline Саратовская & 369 & 38 & 4 & - & - & - & 327 & 39 & 288 \\
\hline Ульяновская & 167 & 21 & 3 & - & - & - & 143 & 31 & 112 \\
\hline
\end{tabular}

Источники: Статистический бюмлетень «Формирование местного самоуправления в Российской Федерации на 1 января 2015 г.»; Статистический бюметень «Формирование местного самоуправления в Российской Федерации на 1 января 2017 г.»

Серьезные экономические трудности дмя слаженной работы органов мест- 
ного самоуправления и ТОС связаны с отсутствием в законодательстве механизмов межбюджетной подАержкии муниџипацитетов, что приводит к тому, что муниџипальные образования, цидирующие по привлечению инвестиџий в регионе, могут получить от регионацьных вцастей как финансовую поддержкку, так и отказ [6, с. 26].

Многие ТОСы сталкиваются с проблемами такого рода: слабая информированность и низкая мотивация населения, недостаточно высокий уровень правовой грамотности; активность мидера разбивается об инертность житемей; в бюАжетах муниципальных образований не предусматриваются средства на развитие ТОС; отсутствуют Аолгосрочные программы по развитию своих территорий; низкий уровень правовой и коммуникативной компетентности уполномоченных выборных $и ц$ ТОС и чиенов органов ТОС требует дополнительного образования; отсутствует система поощрений кучших практик; органы местного самоуправления, с одной стороны, поддержкивают ТОСы, а с Аругой - ограничивают их полномочия, опасаясь порождения альтернативного органа вмасти [7, с. 140-141]. Аругими словами, территориальное обшественное самоуправление осуществляется в поле ограниченных полномочий, широкой ответственности и серьезных рисков. ОАно из возможных решений - освоение проектных технологий и практик.

По инициативе и поддержке руководства Ассоциации Совета муниципальных образований Саратовской обмасти Амя Шкомы ТОС в 2017 г. группой преподавателей Поволжского института управления имени П.А. Столыпина РАНХиГС (А-р соџиол. наук, проф. Т.И. Черняева, канА. экон. наук, Аоц. Г.Г. Паничкина, канд. фимос. наук, Аоџ. Ю.А. Корсаков) была разработана и реацизована программа проектной сессии «Организаџионно-управленческое проектирование в системе территориацьного общественного самоуправления». Формулировка темы обусловлена факторами общественного, государственного и муниципацьного характера. Реацьное формирование гражданского общества актуализирует использование эффективных технологий соџиального взаимодействия, ориентированных на результативное изменение ситуации в соџиальной среде. Руководство страны и регионов в последние годы активно внеАряют институты и идеологию проектного управцения в органах исполнительной власти Российской Федераџии всех уровней. Профессиональный рост и мичностное развитие муниципальных служащих, занятие интересным делом, самореализация нуждаются в оформлении, обеспечивающем эффективную коммуникацию с партнерами. ПреАставители ТОС и органов МСУ - участники проектной сессии - явцяются теми субъектами, Аця которых овцадение и испоцьзование проектной технологии значимо и перспективно в общем процессе развития территорий, повышения качества жизни в населенных пунктах Саратовской области.

В рамках проектной сессии использовалась оригинацьная методика «пошагового» освоения технологии организационно-управленческого проектирования (ОУП). Основу ОУП составцяют анациз соџиацьной и управленческой ситуаџии; структурирование проблемного поля и выявление 
целевых групп, заинтересованных в решении насущных проблем; формирование команд, ориентированных на достижение целевых ориентиров проекта (связанных с изменением ситуации) как своих цичных целей; организационно-управленческое, ресурсное и коммуникационное обеспечение поставленных задач.

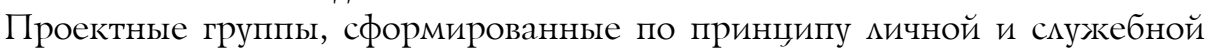
заинтересованности в решении проблемы местного значения, обсуждали и оформияли результаты (в тексте и слайдах презентации) по основным раздемам проектной разработки. Все разделы проекта анализировались на общих конференциях. КажАый последующий «шаг» совершался с учетом критических замечаний по предыдущему разделу. С проектными группами работали модераторы, которые обеспечивали методическую подАержку, внутригрупповые и внешние коммуникаџии в аудитории и дистанџионно.

Организационные вопросы решацись представителями Ассоџиации Совета муниципальных образований Саратовской области (И.В. Ракевич - руководитель аппарата; Ж.В. Поздышева - консультант). Проектная сессия проходила на базе ЦАПО Поволжского института управцения имени П.А. Столыпина РАНХиГС в июле - ноябре 2017 г.

В разработке проектов приняли участие 28 участников (18 - представители ТОС и 10 - сотрудники аАминистраций МО Саратовской области). По итогам сессии к пубцичной защите были представцены пять проектных заявок по следующим темам.

«Формирование кумьтурного бренда территории с использованием информационно-коммуникаџионных технологий в с. Широкое Татищевского района» (разработчики: С.Ю. Андрианова - Татищевский МР; А.П. Землянухина - Аткарский МР; С.В. Попова - ИАогское МО, Татищевский МР; А.Ю. Русскин - Садовское МО, Татищевский МР; С.В. Сацьникова - МО г. Аткарск; В.В. Степанюк - Сторожевское МО, Татищевский МР; модератор - Т.И. Черняева). Цель - разработать концепцию бренда территории и продвигать его, что позволит усилить привлекательность с. Широкое (увеличить участие жителей в брендовых и Аругих массовых мероприятиях не менее чем на 15\%, производство собственной продукции АПХ и преАпринимателей - на 20\%, поток туристов - на $10 \%$, доходы в бюджет муниципацьного образования - на 10\%). Сроки реализации проекта: декабрь 2017 - октябрь 2018 г.

«Вода в каждый дом» (разработчики: Ю.А. Паращукова - Вольский МР; Г.Ф. Симонова - Широкобуеракское МО, Вольский МР; И.С. Харитонов - Барановское МО, Вольский МР; С.Н. Поликарпов - Белогорновское МО, Вольский МР; С.Ф. Коблова - Покровское МО, Вольский МР; С.Н. Хайнова - Свердиовское МО, Калининский МР; В.М. Аоровских - Аекабристское МО, Ершовский МР; модератор - Ю.А. Корсаков). Цель проекта - обеспечить бесперебойное снабжение населения поселка качественной питьевой водой (ремонт системы водоснабжения в с. Покровка Вольского района), используя организационную форму соџиального партнерства. Сроки реализации проекта: 6-30 ноября 2017 г. 
«БАагоустройство родника Гремучий, с. Мордовое, Красноармейский МР» (разработчики: В.А. Калдин - ТОС «Соколовая гора», г. Саратов; А.П. Агарков - ТОС «Зоналка», г. Саратов; М.П. Резвова - ТОС «Зеленый квартам», п. Новопушкинское, Энгельский МР; Н.И. Косиџына - ТОС «Исток», с. Мордово, Красноармейский МР; модератор - Г.Г. Паничкина). Цель проекта - благоустроить территорию вокруг родника (1564 кв. м), сделать родник более привлекательным местом Аля жителей села и туристов (что позволит обеспечить участие не менее 50\% жителей села в мероприятиях, проводимых у родника; увеличит приток посетителей-туристов на 10\%). Сроки: 1 ноября 2017 - 30 апремя 2018 г.

«Память серАџа (обустройство кладбища сельского поселения)» (разработчики: Н.А. Сажнева - ТОС с. Аммазово, Пинеровское МО, Балашовский МР; В.В. Гаврин - ТОС с. Миморадовка, Краснопартизанский МР; Г.З. Якимова - ТОС с. Сулак, Краснопартизанский МР; М.А. Конотопко - администрация Гвардейского МО, Красноармейский МР; модератор - Ю.А. Корсаков). Цель - обустройство территории кмадбища с. Алмазово как компонента мемориальной культуры совместными усилиями граждан и аАминистраџии Пинеровского МО. Сроки реализаџии проекта: 1 марта - 30 августа 2018 г.

«Семейный парк» (разработчики: О.А. Казакова - ТОС Натальинского МО, Балаковский МР; О.Н. Холопова - ТОС Красноярского МО, Энгельсский МР; Е.В. Ночевная - ТОС Терновского МО, Энгельсский МР; Р.А. Абилов - ТОС Терновского МО, Энгельсский МР; Р.Ф. Халимов - аАминистрация Усть-Кураюмского МО, Саратовский МР; В.Н. Титаев житель с. Усть-Курдюм; И.М. Тарасова -ТОС п. Грачи Натальинского МО, Балаковский МР; модератор - Т.И. Черняева). Цель проекта - благоустройство территории пмощадью 1500 кв. м Аля созАания Семейного парка и привлечение не менее $50 \%$ населения с. Натальино дмя совместных работ. Сроки: январь - декабрь 2018 г.

Разработанные проектные документы (тексты, презентации) свидетельствуют о том, что участники программы ознакомились с особенностями организаџионно-управленческого проектирования и освоили технологию работы проектных команд. Последнее особенно важно, поскольку стратегией реализации всех проектов явмяется формирование институций партнерства (координационных советов, инициативных групп, проектных команд), обеспечивающих сотрудничество граждан и органов местного самоуправления. Проектная культура, ее принципы, нормы и язык могут стать инструментом и ресурсом успешного взаимодействия.

Все проекты направлены на решение актуальных проблем местного значения, конкретной территории. В связи с этим отметим наличие во всех проектах раздела, обосновывающего реальность и приоритетность выбранной проблемы. Навыки формулировки проблемы - первый шаг в объединении усилий стейкхолдеров по ее решению. Разработчики проектов продемонстрировали начальные умения структурировать целевые ориентиры, 
обеспечивать поставленные задачи необходимыми ресурсами. Почти все проектные идеи, несмотря на привязку к конкретной территории, имеют мультипликативный эффект, то есть могут быть реализованы в других цокациях, стать примером организаџии работ по благоустройству территории, формированию бренда посемения, изменению имиджа органов управмения МО. ГАавное - в проектах предкагаются варианты решения задачи по развитию и поддержке иниџиативы и гражданской активности, повышения качества повседневной жизни.

Представленные проектные разработки по структуре и содержанию могут быть отнесены к проектным заявкам, поскольку ряд компонентов полноценного проекта (например, бюАжет, коммуникации, риски, оџенка эффективности) отражены обобщенно и в неполной степени. ОАнако дия привлечения внимания заинтересованных киџ и организаций (стейкхомдеров) к актуальной проблеме, демонстрации проектной идеи и ее разнопланового обоснования, Аля объединения усилий граждан и администрации МО по достижению поставленных целей они вполне пригодны.

Формирование проектных команд из преАставителей размичных ТОС и МО имеет как свои достоинства, так и недостатки. Поскольку проект привязан к конкретной проблеме определенной территории, то мотивация чиенов группы и активность участия в разработке проектной идеи могут существенно снижаться. Ограниченность (скорее, недостаточность) времени взаимодействия не позволяет создать эффективную проектную команАу, что, в свою очередь, влияет на качество проекта и глубину освоения участниками проектной культуры и технологии. Эффективная организация проектной сессии ограничивается нерешенностью цогистических проблем (расписанием автобусов) и занятостью участников программы по месту основной работы.

Результаты проведения проектной сессии по заявленной программе демонстрируют ее востребованность и одновременно неиспользованные потенциалы. ОАним из возможных вариантов решения названных проблем может быть организаџия непрерывного 2-3-дневного обучения преАставителей ТОС и МО проектированию с выездом в Саратов, а в последующем организация конкурса проектов ТОС (МО) с финансированием проектов-победителей из регионального бюАжета.

Анализ опыта органов общественного управления Франции показывает эффективность гибридной модели мидерства. Интегральная модель территориального мидерства включает три основные измерения: обеспечить развитие и поддержку территориальных стейкхомдеров (с учетом их интересов); стать центром территориальных преобразований / качественных изменений); удерживать мидерство во взаимодействиях с кмючевыми акторами [8]. Аля территорий задача не только выжить, но и достичь мидирующих позиций в пространственном развитии страны означает прежде всего поАготовку мидеров преобразований, способных генерировать новые смыслы и порождать новые практики в системе территориального общественного самоуправцения. 


\section{Библиографический список}

1. Положение о содержании, составе, порядке разработки и утверждения Стратегии пространственного развития Российской Федерации и подготавливаемых в ее составе предложений о совершенствовании системы расселения на территории Российской Федерации и приоритетных направлениях размещения производительных сил на территории Российской Федерации: утв. постановлением Правительства РФ от 20 авг. 2015 г. № 870. URL: http:// economy.gov.ru/minec/resources/707c3511-7cf9-466c-baa8-7bf567786326/

2. Пространственное развитие России: вопросы стратегии. URL: http://bujet.ru/article/317108.php

3. Формирование местного самоуправления в Российской Федерации на 1 января 2015 г: статистический бюллетень. URL : http://www.gks.ru/free_doc/doc_2015/mes_upr2015.rar

4. Формирование местного самоуправления в Российской Федерации на 1 января 2017 г: статистический бюллетенью URL : http://www.gks.ru/free_doc/doc_2017/mes_upr2017.rar

5. Развитие ТОС в России. Национальный институт развития современной идеологии. URL: http://www.nirsi.ru/life/razvitie-tos-v-rossii/

6. Кабанова И.Е. Экономическое развитие муниципального образования: баланс государственного управления и местного самоуправления: доклад о состоянии местного самоуправления в Российской Федерации «Изменение баланса интересов государственной власти и местного самоуправления» / под ред. Е.С. Шугриной. М., 2017. С. 20-32.

7. Лаврентьев А.Р., Степанов Д.В., Калянова Ю.Г. Доклад о состоянии местного самоуправления в Нижегородской области // Доклад о состоянии местного самоуправления в Российской Федерации «Изменение баланса интересов государственной власти и местного самоуправления» / под ред. Е. С. Шугриной. М., 2017. С. 113-141.

8. Arnaud Ch., Soldo E. Towards territorial leadership: missions and roles of territorial public organizations (TPO) // International Review of Administrative Sciences. Preview. First Published November 29, 2017. URL: http://journals.sagepub.com/doi/pdf/10.1177/0020852317723713

32 Bulletin of the Volga Region Institute of Administration • 2018. Vol. 18. № 1 